\title{
(6) OPEN ACCESS \\ A matter of life and death: controversy at the interface between clinical and legal decision-making in prolonged disorders of consciousness
}

\author{
Lynne Turner-Stokes ${ }^{1,2}$
}

\begin{abstract}
- Additional material is published online only. To view please visit the journal online (http://dx.doi.org/10.1136/ medethics-2016-104057)

${ }^{1}$ Faculty of Life Sciences and Medicine, Department of Palliative Care, Policy and Rehabilitation, King's College London, London, UK 2Regional/Hyper-acute Rehabilitation Unit, Northwick Park Hospital, Harrow, UK
\end{abstract}

\section{Correspondence to} Professor Lynne Turner-Stokes, Regional Rehabilitation Unit, Northwick Park Hospital Watford Road, Harrow, Middlesex HA1 3UJ, UK; lynne.turner-stokes@doctors. org.uk,

lynne.turner-stokes@kcl.ac.uk

Received 17 November 2016 Revised 27 November 2016 Accepted 29 November 2016 Published Online First 16 December 2016
CrossMark

To cite: Turner-Stokes L. $J$ Med Ethics

2017:43:469-475.

\section{ABSTRACT}

Best interests decision-making and end-of-life care for patients in permanent vegetative or minimally conscious states (VS/MCS) is a complex area of clinical and legal practice, which is poorly understood by most clinicians, lawyers and members of the public. In recent weeks, the Oxford Shrieval lecture by Mr Justice Baker ('A Matter of Life and Death', 11 October 2016) and its subsequent reporting in the public press has sparked debate on the respective roles of clinicians, the Court of Protection and the Mental Capacity Act 2005 in decisions to withhold or withdraw life-sustaining treatments from patients with disorders of consciousness. The debate became polarised and confused by misquotation and inaccurate terminology, and highlighted a lack of knowledge about how patients in VS/MCS die in the absence of court approval. This article sets out the background and discussion and attempts to give a more accurate representation of the facts. In the spirit of transparency, I present a mortality review of all the patients in VS/MCS who have died under the care of my own unit in the last decade - with or without referral to the court, but always in accordance with the law. These data demonstrate that clinicians regularly undertake best interests decision-making in conjunction with families that may include life and death decisions (sometimes even the withdrawal or withholding of clinically assisted nutrition and hydration); and that these can be made within the current legal framework without necessarily involving the court in all cases. This is the first published case series of its kind.

\section{BACKGROUND}

As ambulance and acute care services become ever more efficient at saving lives, a large number of people who would otherwise have died from catastrophic injury or illness go on to make a good recovery. Many patients experience a brief period of unconsciousness lasting a few days or weeks. However, an unfortunate few with very severe brain injury remain in a prolonged disorder of consciousness for many months-or in some cases permanently.

The Royal College of Physicians (RCP) National Clinical Guidelines for Prolonged Disorders of Consciousness (PDOC) ${ }^{1}$ define three levels of disordered consciousness as set out in table $1 .{ }^{i}$

'These are distinct from 'locked-in syndrome' (in which patients are conscious but near-totally paralysed) or 'brain-stem death' (in which all brain-stem functions are lost, including spontaneous respiratory effort).
Unfortunately, the lay literature, and even much of the medical literature, tends to conflate coma with persistent vegetative state (VS). ${ }^{2}$ True coma (with absent wakefulness and absent awareness) rarely persists for more than a few days or weeks, unless accompanied by aggressive life support. The large majority of patients will either die (usually from pneumonia or brainstem dysfunction) or start to regain consciousness. While some will emerge to full consciousness, a small number will remain in a permanent VS or minimally conscious state (MCS) for the rest of their lives-and many will live for a decade or more in this condition. ${ }^{3}$

Despite increasingly sophisticated techniques for imaging, investigation and clinical assessment of patients with sudden onset brain injury, there is currently no reliable way to predict outcome. ${ }^{4}$ Therefore, active medical treatment is normally provided during the early stages in the hope and expectation of recovery. But, in some cases, this treatment will be 'futile' in restoring the patient to a quality of life that they would consider worthwhile. For medical treatments to be 'proportionate', the benefits must outweigh the burdens, which may vary depending on the individual's values and preferences. ${ }^{4}$ A treatment may have 'substantial benefit' if it produces an outcome that the patient would consider worthwhile, either now or in the future. ${ }^{5}$ On the other hand, clinicians must also consider the 'risk of unacceptable badness' - the probability that the patient will end up living in a state that they would describe as intolerable. These concepts have been extensively discussed in the context of rescue surgery (eg, decompressive craniectomy) following acute neurotrauma. ${ }^{7}{ }^{8}$ However, they apply similarly to all life-preserving treatments. If it becomes clear that a patient is unlikely to regain consciousness, or that further life-sustaining treatment would be 'futile' or 'disproportionate' in the terms described above, family members and the treating team may come to the conclusion that the person would not wish to continue to receive that treatment, but would prefer to be allowed to die naturally.

\section{Withdrawal of life-sustaining treatment in patients in VS and MCS}

By definition, patients in VS and MCS lack the mental capacity to make decisions regarding their care and treatment. The Mental Capacity Act $2005^{9}$ requires that all such decisions should be made for them on the basis of their best interests, taking into account their values, wishes and beliefs —insofar as these can be known. Family members 
Table 1 Definitions of disorders of consciousness*

\begin{tabular}{|c|c|}
\hline $\begin{array}{l}\text { Coma (absent wakefulness and } \\
\text { absent awareness) }\end{array}$ & $\begin{array}{l}\text { A state of unrousable unresponsiveness, } \\
\text { lasting }>6 \text { hours in which a person: } \\
\text { cannot be awakened } \\
\text { fails to respond normally to painful } \\
\text { stimuli, light or sound } \\
\text { lacks a normal sleep-wake cycle } \\
\text { does not initiate voluntary actions }\end{array}$ \\
\hline $\begin{array}{l}\text { Vegetative state (VS) (wakefulness } \\
\text { with absent awareness) }\end{array}$ & $\begin{array}{l}\text { A state of wakefulness without awareness } \\
\text { in which there is preserved capacity for } \\
\text { spontaneous or stimulus-induced arousal- } \\
\text { evidenced by sleep-wake cycles and a } \\
\text { range of reflexive and spontaneous } \\
\text { behaviours. } \\
\text { VS is characterised by complete absence of } \\
\text { behavioural evidence for self-awareness or } \\
\text { environmental awareness }\end{array}$ \\
\hline $\begin{array}{l}\text { Minimally conscious state (MCS) } \\
\text { (wakefulness with minimal } \\
\text { awareness) }\end{array}$ & $\begin{array}{l}\text { A state of severely altered consciousness in } \\
\text { which minimal but clearly discernible } \\
\text { behavioural evidence of self-awareness or } \\
\text { environmental awareness is demonstrated } \\
\text { MCS is characterised by inconsistent, but } \\
\text { reproducible, responses above the level of } \\
\text { spontaneous or reflexive behaviour, which } \\
\text { indicate some degree of interaction with } \\
\text { their surroundings }\end{array}$ \\
\hline
\end{tabular}

*Adapted with permission from the RCP PDOC guidelines.

PDOC, Prolonged Disorders of Consciousness; RCP, Royal College of Physicians.

play a critical role in best interests decision-making as, in the absence of clear written instruction, they are often best placed to provide information about the patient's prior values and beliefs. ${ }^{10}$

Patients in VS and MCS frequently have medical comorbidities and, as part of clinical treatment planning for all patients with serious illness or injury, it is appropriate to consider the ceiling of care-particularly for decisions that may require 'out-of-hours' intervention by emergency teams who are unfamiliar with the patient. ${ }^{1}$ Key decisions may include whether or not to use antibiotics in the instance of life-threatening infection; cardiopulmonary resuscitation in the event of cardiac arrest or to escalate to emergency or intensive care settings if they become unstable. Such decisions will need to take account of the likely success, benefits, burdens and risks of treatment as well—as the patient's presumed wishes, and their timing will vary depending on the stage in the care pathway. The RCP PDOC guidelines recommend that best interests discussions should occur as a matter of routine clinical practice to establish an appropriate ceiling of care depending on the patient's condition and stage of care. ${ }^{1}$

In England ${ }^{11}$ an exception to this clinical decision-making is the withdrawal of clinically assisted nutrition and hydration (CANH) - (or 'artificial nutrition and hydration' (ANH), as it used to be known). CANH is considered a medical treatment because it is given through an enteral feeding tube (either a nasogastric tube or a gastrostomy), which requires clinical intervention for insertion and replacement of the tube, as well as for the administration of feeds. Practice Direction 9E of the Court of Protection (CoP) Rules describes court applications relating to serious medical treatments (2007). ${ }^{12}$ Section 5 states that "cases involving any of the following decisions should be regarded as serious medical treatment for the purpose of the rules and this practice direction, and should be brought to the court: (a) decisions about the proposed withholding or withdrawal of artificial nutrition and hydration from a person in a permanent VS or a MCS'.
This requirement stems from the cases of Airedale NHS Trust v Bland [1993] AC 789, and W v M [2011] EWHC 2443 (COP) and is driven by the fact that, unlike other medical decisions that carry a certain element of chance, death will inevitably occur within 2-3 weeks of CANH withdrawal in a patient who might otherwise live for years. Therefore, it is considered that these decisions require additional scrutiny by the CoP in order to be declared lawful, although some argue that use of the word 'should' makes this a recommendation for good practice rather than a legal requirement. ${ }^{13}$

While the logic of this is clear, the practicality and ethics leave much to be desired. Technically, once a clinical decision has been made that a given treatment is not in the patient's best interests, continuing to administer that treatment constitutes an assault. ${ }^{14}$ Even when all parties (including the family and treating team) are in complete agreement, and have obtained a confirmatory opinion from an independent expert, the process of obtaining 'declaratory relief' from the court can be timeconsuming as well as expensive. A large body of evidence must be assembled for the application, with witness statements from the family members and care staff, reports from the clinical team and independent expert, copies of the medical notes and structured assessment tools, etc. The Official Solicitor then typically commissions a third expert opinion who reviews all of the relevant data (in addition to visiting the patient and conducting their own discussions with the healthcare team and family members) to confirm again the diagnosis and opine on the patient's best interests. The hearing is conducted in public, and is thus dependent on the court timetable. A recent study from the University of York ${ }^{15}$ showed that the average time taken for this 'declaratory relief' process in a VS case is about 9 months and costs to the National Health Service about $£ 122000$ (comprising $£ 53000$ in legal costs and $£ 69000$ in ongoing care costs during the waiting period). Moreover, while the court application is in process, clinical teams have sometimes been required by the Official Solicitor to provide further treatments that would otherwise have fallen above the planned ceiling of care. ${ }^{16}$

While this time scale might arguably be acceptable for patients who may otherwise live for many years, it is clearly not appropriate for others. The RCP PDOC guidelines endorsed the need for court application for withdrawal of $\mathrm{CANH}$, but the guidelines also made very clear that they applied only to patients in permanent VS or MCS following sudden-onset acquired brain injury. In clinical practice, disordered consciousness may occur in many other contexts. Coma, for example, is a very common terminal state in many types of condition apart from brain injury. It rarely lasts for very long, and clinical staff routinely make pragmatic and sensible best interests decisions in conjunction with patients' families about withholding medical interventions (including $\mathrm{CANH}$ ) without reference to the court. Similarly, other low awareness states (with or without wakefulness) can occur as part of a progressive decline at the end of life in older patients with chronic degenerative conditions including dementia, Parkinson's disease, multiple strokes, etc. The courts would be overwhelmed if all of these cases required declaratory relief, and many patients would not live long enough for a judgement to be declared so that much of the time and effort would be wasted.

In order to address the delays imposed by the court process, a group of clinicians and lawyers was recently convened to try to develop a 'fast-track' process for applications for CANH withdrawal in undisputed cases of permanent VS only. The group included experienced clinical experts, lawyers and family representatives; alongside senior representatives of the judiciary, CoP 
Rules Committee and the Official Solicitor. The proposed fasttrack system did not attempt to 'cut corners', but to specify clearly the necessary opinion, documentation and supporting evidence required and to present this in a consistent, logical and easily navigable form (available at http://cdoc.org.uk/ publications/resources-for-families-and-practitioners/).

Key features of the fast-track process are outlined in table 2 . This would help at least to avoid the current delays caused by having insufficient evidence presented at court, requiring adjournment until further evidence can be obtained. ${ }^{16}$ This proposal was put to the CoP Rules Committee nearly a year ago, but sadly has not yet been adopted. Although the committee agreed to it being piloted in the meantime, the Official Solicitor has declined to participate in the pilot process, so currently this is on hold with no immediate likelihood of resolution.

In the meantime, individuals can take steps to ensure that their wishes regarding care and treatment are met following loss of capacity by drawing up an Advance Decision to Refuse Treatment (ADRT) or by appointing a Lasting Power of Attorney for Health and Welfare, with appropriate instruction. Both of these can include decisions regarding life-sustaining treatments so long as this is expressly stated in the documentation. The Mental Capacity Act 2005 (Sections 24-26) gives Advance Decisions statutory force in England and Wales. An adult with the capacity to make treatment decisions can make an ADRT in the event that they cannot later make or communicate that decision themselves. As long as the ADRT meets the strict requirements for being valid and applicable, doctors are legally bound by and must respect it.

Table 2 Key features of the proposed fast-track application for withdrawal of CANH

\section{Preconditions}

1 The patient is confirmed as being in a permanent vegetative state from which recovery of awareness is highly improbable

2 There is no dispute that withdrawal of CANH is in the patient's best interests, taking into account their likely wishes, values and beliefs, so far as these are known

3 Appropriate plans are in place for management of end-of-life care according to best practice, including backup plans for specialist support

Diagnosis

4 There has been an adequate time frame for improvement-at least 6 months post-non-traumatic brain injury, or 12 months post-traumatic brain injury

5 The patient has undergone an adequate period of assessment by appropriately trained and experienced PDOC assessors in a designated specialised PDOC unit (or by a specialist PDOC outreach service)

6 Assessment has been conducted according to the RCP guidelines using two or more of the approved structured assessment tools:

The Wessex Head Injury Matrix administered serially over time, at least two to three times per week over 4 weeks

The Coma Arousal Scale-Revised at least 10 times over 4 weeks The Sensory Modality Assessment and Rehabilitation Technique

Confirmation

7 The above must be confirmed by two independent physicians who meet the requirements for experience and training in PDOC, as set out in the RCP PDOC guidelines

8 Their assessment confirms that the conditions above have met the standards of best practice as laid out in RCP PDOC guidelines including:

A. the conditions for diagnosis of a permanent vegetative state

B. procedures for conducting and documenting best interests decision-making meetings

C. plans for end-of-life care

CANH, clinically assisted nutrition and hydration; PDOC, prolonged disorders of consciousness; RCP, Royal College of Physicians.

\section{CONTROVERSY: THE OXFORD SHRIEVAL LECTURE AND} SUBSEQUENT DEBATE

Mr Justice Baker's Oxford Shrieval lecture ${ }^{17}$ (October 2016) provided a clear and well-constructed resumé of the history and legal arguments for the requirement for court approval for withdrawal of CANH from patients in VS and MCS. While stressing the need for a more streamlined process, he set out his view that court application should continue to be obligatory, at least for the time being.

He noted that:

some doubt has been expressed as to whether either an advance decision or the power vested in the donee of a Lasting Power of Attorney extends to decisions concerning a proposal to withhold or withdraw ANH. This is because of the terms of the relevant Practice Direction supplementing the rules governing applications relating to serious medical treatment (footnote to section 5a PD9E, 2015). It is to say the least unfortunate that there should be such uncertainty and it is to be hoped that the opportunity will arise soon for the courts to resolve this question. So far as I am aware, there is no instance in this country of a case in which $\mathrm{ANH}$ has been withheld or withdrawn from a patient suffering from a disorder of consciousness without reference to the court.

This statement set a number of hares running in the public press.

Steve Doughty (Daily Mail 24 October 2016) wrote an article entitled 'Don't obey orders in a living will, judge orders doctors: Ruling means patients in an unconscious state cannot die without the case going before a court', with subheading 'No one in a coma should be allowed to die without the case going to court'. The article suggested that the recent update of Practice Direction 9E by Sir James Munby (President of the Family Division) in 2015 constituted a new ruling-now supported by Mr Justice Baker-that ADRTs refusing CANH require the prior approval of the CoP.

In fact, as pointed out by Ruck Keene,$^{18}$ Practice Direction 9E has always been silent on this matter and the 2015 update to the 2007 Practice Direction 9E was re-issued solely to make reference to the change in the Official Solicitor's address. In his view, Mr Justice Baker was not suggesting that ADRTs should not be followed, he was merely pointing out an apparent inconsistency, in respect of permanent VS and MCS only, which may require correction by the courts. Other sources were also quick to point out that this was a lecture given by a judge and not a ruling or a change in the law ${ }^{19}$ and that $\mathrm{CoP}$ does not have the power to over-rule an Act of Parliament, even should it wish to do so.

Unfortunately, a moment of uncharacteristically imprecise language in Mr Justice Baker's lecture led to further confusion. Having previously quoted the RCP PDOC guidelines and defined the three levels of disorders of consciousness as set out in table 1, he went on to say "So far as I am aware, there is no instance in this country of a case in which ANH has been withheld or withdrawn from a patient suffering from a disorder of consciousness without reference to the court." What he meant to say (as he was kind enough to confirm in a personal communication 17 October 2016) was that he was not aware of ANH having been withheld or withdrawn from a patient suffering from 'a permanent VS or MCS as defined by the RCP guidelines without reference to the court'-coma being a very common presentation in the final stages of life in very many conditions, for the reasons noted above. But sadly this small slip of the tongue served to fuel the flames of controversy.

An article by Frances Gibb in the Times newspaper (26 October 2016) entitled 'End of Life Cases must go to Court' 
picked up on the story. The article, which referred to 'killing of patients by withdrawal of nutrition and hydration tubes', and the Mental Capacity Acts as 'a law for euthanasia by the back door' made no mention of the context for the lecture being VS or MCS. Instead, it declared that “...They [judges] advise that no one who is in a coma or an unconscious state should be allowed to die without the case first being considered by a court”.

A letter to the Editor in response from John Chisolm, Chairman of the British Medical Association (BMA) Ethics Committee (Times, 26 October 2016) provided the following clarification:

\begin{abstract}
The requirement to go to court before medical treatment is withdrawn in some parts of the UK extends only to the withdrawal of artificial nutrition and hydration from patients in a permanent vegetative state or a minimally conscious state.
\end{abstract}

Other treatment decisions on behalf of adults who lack capacity are made, without recourse to the courts, on the basis of whether continuing treatment is in their best interests, or on the basis of a valid advance decision to refuse treatment (ADRT), which is legally binding on health professionals.

This is not about 'killing' patients as this article [Gibb, October 26th 2016] suggests, but about withdrawing those treatments that are not able to provide a benefit to the patient, in some circumstances allowing them to die. This is an intrinsic part of good clinical practice.

A subsequent Times article by Frances Gibb (Who decides matters of life or death? 17 November 2016) provides a much more balanced account of the debate, but still includes an error of terminology. Quoting Baroness Finlay she says “The judge's comments refer only to 'the very small number of people who tragically fall into a persistent vegetative or minimally conscious state"'. Actually they refer only to patients in a permanent VS or MCS.

\section{CASES NOT INVOLVING APPLICATION TO THE COURT}

Ruck-Keene noted that current prevalence estimates in the UK range from 4000 to 16000 patients in VS, with three times as many in MCS. ${ }^{20}$ By contrast, his search of Bailii and Westlaw found only around 10 cases where permission has been sought to withdraw CANH from a person in a permanent VS or MCS since the CoP practice directions were published in October 2007. He deduced from these figures that there must have been a number of cases (perhaps a significant number), where the involvement of the court has not been sought prior to withdrawal of CANH.

He is, of course, correct-although possibly not quite in the manner suggested-as I will show in the last section of this article. Through the presentation of real-life clinical data, I will demonstrate that clinicians regularly undertake best interests decision-making in conjunction with families to weigh up the balance of benefits and harms and determine whether or not to give medical treatments. This may include life and death decisions (sometimes even the withdrawal or withholding $\mathrm{CANH}$ ), which can be made within the current legal framework, without necessarily involving the court in all cases.

Setting out my credentials as a consultant clinician and academic with a particular interest in PDOC, I have worked in this area for over 25 years; I regularly act as a medical expert in court applications for withdrawal of CANH and I was the lead author for the RCP PDOC guidelines. On this basis, I believe that I am conscientious in discharging my responsibilities both with respect to the law and to the clinical and ethical care of my patients and their families. I provide a brief mortality review of the patients in PDOC, who have died under the care of my own unit over the course of the last 10 years. This may hopefully provide a better understanding of the challenges and realities of managing end-of-life best interests decisions for this patient group in clinical practice. To my knowledge, this is the first published case series of its kind.

\section{Setting}

The Regional Hyper-acute Rehabilitation Unit (RHRU) at Northwick Park Hospital is a 24-bedded tertiary specialist inpatient neurorehabilitation unit in northwest London. It has three consultants in rehabilitation medicine and a multidisciplinary team of experienced nursing and therapy staff across the range of disciplines. The unit started to take patients in VS/ MCS in 2007 and is now one of two designated units in London for the assessment and management of patients in PDOC. The unit also provides end-of-life neuropalliative care for patients dying from catastrophic brain injury, including on occasion withdrawal of CANH. We also provide outreach advice and support to other services (including nursing homes and hospices) for end-of-life care following elective court-approved withdrawing of CANH.

Our end-of-life care programme is provided in accordance with the RCP PDOC guidelines. ${ }^{1}$ The programme includes a careful review of each medical treatment to consider whether or not it is in the patient's best interests to continue to give it. The majority of patients die from intercurrent illness, such as sepsis, respiratory failure or a further cerebral event. CANH is not routinely removed during end-of-life care, but may be reduced or stopped if the patient is unable to tolerate it; or if it is decided to be in the patient's best interests (and of course permissible within current law) to do so.

\section{Mortality review}

A systematic search of our unit's clinical database was conducted to identify all patients admitted to our PDOC assessment programme who died either while on our unit or within 1-2 weeks after discharge to long-term care. A total of 165 patients were admitted during the 10-year period (2007-2016), of whom 23 (14\%) died. Of these, nine (39\%) were still in VS when they died, nine (39\%) were in MCS; three had emerged into consciousness but remained profoundly disabled, and two were in coma. Their mean age was 45 years (SD 13, range 21-63). At death, the mean time from onset of injury was 8 months (SD 18, range 2-32). Details of their underlying conditions and mode of death are given in online supplement 1 .

The clinical records were examined to identify the mode of death and any end-of-life decision-making. The exact mode of death is only known for the 14 who died while actually on the RHRU. The most common cause of death was pneumonia (9/14 cases (64\%)). Others were sepsis, cardiac failure, hypoxia and multiorgan failure. Online supplement 1 also demonstrates the complex array of medical conditions from which many of these severely brain-injured patients suffer.

Three died unexpectedly, but 11 (79\%) were on a formal neuropalliative programme, which included a best interests decision to withdraw or withhold some form of medical interventiontypically a decision to withhold antibiotics, surgery or active resuscitation. In four patients, this included withholding or withdrawal of CANH, of which only one had court approval, so this merits further explanation. 
Of the three without court approval, two of them (cases 9 and 11) had severe intra-abdominal pathology with total bowel obstruction and/or peritonitis following previous abdominal surgery. Further surgical intervention was inappropriate due to the low long-term likelihood of success and the high operative and anaesthetic risk. Inoperability was confirmed by independent surgical opinion. CANH was withdrawn/withheld because it was impossible to administer in these cases. Best interests decisions were made in conjunction with their families to transfer them to a neuropalliative programme and they both died peacefully 2 weeks later. The third is the recent case of a woman aged 61 years who was in coma (rather than VS or MCS), for whom we made a best interests decision to withdraw life-sustaining treatment. With her family's permission, her case is described in detail below.

\section{Case study}

Mrs A (not her real initials) was involved in a pedestrian versus car road traffic accident in March 2014. She sustained a left subdural haematoma, a right frontal contra-coup injury and traumatic intraparenchymal and subarachnoid haemorrhage. She was admitted to a major trauma centre, where she underwent decompressive craniectomy with evacuation of haematoma and removal of frontal contusions. Her subsequent clinical course was complicated by an additional hypoxic brain injury secondary to mucous plugging and cardiac arrest. She also developed hydrocephalus for which she had a ventriculoperitoneal shunt inserted. Six months after her initial injury she required surgery for a further right extradural collection. One year after admission she developed cranial sepsis due an infected cranioplasty requiring prolonged intravenous antibiotics and flap removal. In February 2016, nearly 2 years after her original injury, she was transferred to a long-term care facility.

Sadly, she never recovered full consciousness. She had a tracheostomy and a percutaneous gastrostomy for enteral feeding. At her best she had only limited awareness, but there had been a progressive downhill trend, which was not unexpected given her multiple cerebral pathologies. By summer 2016, she was making no response at all other than to cough and display abnormal posturing when being handled or receiving tracheostomy care. These responses were perceived as pain/ discomfort and she was placed on morphine (20 mg/24 hours) and midazolam ( $15 \mathrm{mg} / 24$ hours) by syringe driver.

Her family was very clear that she would not want to continue to be kept alive artificially under these circumstances. They and her local treating team were in all agreement that it was no longer in her best interests to continue life-sustaining treatment.

Figure 1 Line graph of Mrs A's Wessex Head Injury Matrix (WHIM) scores. The WHIM scores show a flat trace with zero behaviours recorded other than grinding of her teeth (WHIM item 7) during the first two assessments. Her scores remained unchanged after stopping the sedative medication.
At that time she was thought to be in permanent VS and her local team sought advice about a court application to withdraw CANH. They were informed that the diagnosis could not be confirmed without first withdrawing her morphine and midazolam, but were understandably concerned about the ethics and practicalities of this approach and they approached me for advice. Mrs A was subsequently admitted to my unit for assessment and a second opinion regarding her best interests with respect to further management.

After best interests discussion, we agreed to withdraw the morphine and midazolam under close supervision, provided that she did not show signs of excessive distress. Over a 3-week period, we conducted a detailed clinical assessment (including the use of validated tools: the Wessex Head Injury Matrix (12 ratings-see figure 1) and the Coma Recovery Scale-revised (14 ratings) in accordance with the RCP guidelines. We found that she had actually deteriorated into coma (with no sleep/wake cycles), and this state of coma persisted even after the morphine and midazolam had been withdrawn for more than a week.

Further best interests discussions were held with her family, her local team and the RHRU team (including all three consultants). Her husband told us that she had been a very active and highly respected lady, would have been devastated by her current condition. She had a strong Christian faith and that death had no terrors for her. All parties were in agreement that it was not in her best interests to continue life-sustaining treatment, and that she should be allowed to pass away naturally.

As she was now in coma (rather than permanent VS or MCS), it was agreed that this fell outside the stipulations of the CoP Practice Direction 9E, and did not require application to the court. This was confirmed in consultation with the Trust's legal team and also with the BMA Ethics and Human Rights Department. It was therefore agreed by all parties to review and withdraw life-sustaining treatment under a formal neuropalliative care programme to allow her to die a peaceful and dignified death. Given our specialist experience in this area, her family chose for her to remain on the RHRU for this final stage.

Her end-of-life care programme was started in the fifth week of her admission. Even where there is no evidence of awareness, it is accepted best practice to give analgesia and sedation to manage any signs of physiological distress. The RCP PDOC guidelines provide a detailed protocol and offers the choice of subcutaneous or intravenous administration. On the RHRU, we prefer to use the intravenous route where possible, as the quicker absorption allows more accurate and titratable symptom control in accordance with need. Her care regimen is summarised in table 3 . 
Table 3 Mrs A's end-of-life care programme

\begin{tabular}{|c|c|}
\hline Preparation & $\begin{array}{l}\text { Her subcutaneous infusion of morphine ( } 20 \mathrm{mg} / 24 \text { hours) and midazolam ( } 15 \mathrm{mg} / 24 \text { hours) via a syringe driver was re-instated after confirming } \\
\text { the diagnosis of coma. } \\
\text { These were continued while a midlength intravenous line was requested. }\end{array}$ \\
\hline Day 1 & $\begin{array}{l}\text { Clinically assisted nutrition and hydration was discontinued } \\
\text { Her gastrotomy tube was sealed and covered with an occlusive dressing }\end{array}$ \\
\hline Day 2 & $\begin{array}{l}\text { Once the intravenous line was in place, she was changed over to intravenous infusion (morphine ( } 30 \mathrm{mg} / 24 \text { hours) and midazolam ( } 20 \mathrm{mg} / 24 \text { hours)), with } \\
\text { bolus doses of } 5 \mathrm{mg} \text { each as required }\end{array}$ \\
\hline Day 3 & Glycopyrronium $600 \mu \mathrm{g} / 24$ hours and cyclizine $50 \mathrm{mg}$ prn were added to the regimen. These were given subcutaneously \\
\hline Day 4 & Her suprapubic catheter blocked and a urethral catheter was inserted to keep her dry \\
\hline Day 6 & $\begin{array}{l}\text { Because changing her tracheostomy inner tube continued to cause coughing and abnormal posturing, the tracheostomy was removed on January } 112016 \text {. } \\
\text { The stoma was allowed to remain open to facilitate breathing and sputum clearance, and was just loosely covered with protective sterile gauze, changed as } \\
\text { necessary } \\
\text { Her medications were adjusted to morphine ( } 40 \mathrm{mg} / 24 \text { hours) and midazolam ( } 30 \mathrm{mg} / 24 \text { hours). After this she appeared more settled }\end{array}$ \\
\hline Day 8 & $\begin{array}{l}\text { There was a slight increase in her breathing rate and sweating and she had required two additional bolus doses, so the infusion rates were increased to } \\
\text { morphine ( } 50 \mathrm{mg} / 24 \text { hours) and midazolam ( } 35 \mathrm{mg} / 24 \text { hours) }\end{array}$ \\
\hline Day 9 & $\begin{array}{l}\text { Her breathing had become more laboured and her medication was increased further to morphine ( } 60 \mathrm{mg} / 24 \text { hours) and midazolam ( } 50 \mathrm{mg} / 24 \text { hours) after } \\
\text { which she settled }\end{array}$ \\
\hline Day 10 & She died peacefully in the early hours of the morning \\
\hline
\end{tabular}

She died on day 10 of the end-of-life programme. Because the original brain injury arose from a road traffic accident for which the driver of the vehicle had been sentenced for dangerous driving, her case was referred to the coroner. Her death certificate was issued with the immediate cause of death being bronchopneumonia, and the underlying cause of death her severe brain injury and its subsequent complications.

\section{Reflection and comment}

This was a lady who sustained a catastrophic brain injury and developed multiple cerebral pathologies over the ensuing 2 years, with deterioration into coma. Coma falls outside the stipulated requirement for application to the court, and rightly so because most patients only survive in this state for a matter of days or weeks, which is not compatible with a lengthy court process. Having documented the best interests decision-making process, the focus of attention at this time was correctly on providing the most appropriate clinical management to ensure that her inevitable death was as calm and peaceful as possible. Her two principal life-sustaining interventions were (a) CANH via gastrostomy and (b) her tracheostomy. We considered each of these separately on the basis of her best interests.

The withdrawal of CANH was discussed carefully because (like many other families in this situation ${ }^{21}$ ) some of her family members were initially concerned about the prospect of a slow death due to dehydration and multiorgan failure. They were reassured by the plans to provide close monitoring of symptoms and intravenous analgesia and sedation.

Tracheostomy removal in this context is rarely addressed in the literature, and so worthy of discussion here. The possibility of tracheostomy removal had previously been raised by her family. On admission to the RHRU, she had a productive tracheostomy requiring frequent deep suction (several times an hour), which tended to trigger coughing and abnormal posturing involving violent forward flexion of her whole body. It was distressing to witness and this was the reason why she had been started on morphine and midazolam in the care home. Even after discontinuing deep suction, she continued to react just to changing of the inner tube.

When tracheostomy removal was discussed between her family and treating team, it was not entirely predictable what would happen. Three possible scenarios were considered:
1. There was a small chance that her airway would occlude instantly if there was underlying tracheomalacia or granulation tissue, but this was felt to be unlikely as she had not experienced problems during tracheostomy changes.

2. There was also a chance that she would be unable to clear her secretions and maintain her airway, and that she would develop rapid-onset respiratory failure over a few hours.

3. However, the most likely scenario was that it would make little difference, other than the possibility of developing bronchopneumonia over time.

The decision was made collectively that tracheostomy removal was in her best interests as any of the above scenarios was, if anything, preferable to death from dehydration and multiorgan failure, and all of them could be managed symptomatically with appropriate analgesia and sedation. Because of the uncertainty, we delayed removal of the tracheostomy until her intravenous regimen was properly established and stable, and then I personally removed the tracheostomy in the presence of three senior staff members. In the event, she coughed for a brief period after its removal, but settled with a very modest increase of medication. Thereafter, she appeared noticeably more comfortable without the tracheostomy. Three days later, she developed a gradual increase in respiratory rate, and her peaceful death 5 days after tracheostomy removal was considered to be due to bronchopneumonia. She did not develop the marked weight loss or dryness that accompanies end-stage dehydration, and from a clinical point of view her death was a more peaceful death than we have witnessed from withdrawal of CANH alone. While clearly very sad at her final departure, the poem written by her husband for her Thanksgiving service (Nearly before dearly departed, online supplement 2) gives a flavour of the relief that her family experienced in knowing that she was finally at peace.

\section{CONCLUSION}

The current (somewhat anomalous) requirement for court approval to withhold or withdraw CANH in patients in permanent VS and MCS has left many clinicians confused about what treatment decisions they can make without reference to the court. This paper has highlighted some of the challenges of working at the interface between clinical practice and the law in this highly emotive area. While I acknowledge that patients in this hospital-based unit may be more medically unstable 
than patients in long-term care, the mortality review confirms that patients in VS and MCS often have other life-threatening conditions. It is part of normal good clinical practice to hold documented best interests discussions between the family and treating team and, where appropriate, to agree a ceiling of care -applying to the court only where required by current law to do so, or in cases of dispute. I hope that sharing my experience will encourage other clinicians to share information from their own practice. In the meantime, the real-life data presented here may help to provide the legal profession with some broader insight into the clinical reality of managing neuropalliative care and supporting families in these distressing circumstances.

Acknowledgements In respect of the Oxford Shrieval lecture and subsequent debate, I would like to thank Mr Justice Baker for his excellent and informative lecture; Mr Alex Ruck Keene and Dr John Chisolm for their sensible and helpful responses and Professor Celia Kitzinger for alerting me to the correspondence and for commenting during the drafting of this article. In respect of the mortality review I would like to acknowledge the support of my consultant colleagues Drs Aung Thu and Charlie Nyein and all members of the RHRU team who manage this complex group of patients, and contribute to best interests decision-making on a daily basis. I would also like to thank the unit's research and administrative team who so carefully collect and collate the data. In respect of our detailed case report, I would like to thank the patient's family for giving us permission to tell her story. I would like to thank Drs Ben Braithwaite and Clare Thormod for their support with clinical decision-making and Veronica English from the British Medical Association Ethics and Human Rights Department for advice.

Funding Financial support for the preparation of this manuscript was provided by the Dunhill Medical Trust.

Competing interests None declared.

Ethics approval Harrow Research Ethics Committee 04/Q0405/47.

Provenance and peer review Not commissioned; externally peer reviewed.

Data sharing statement Because of patient confidentiality issues in this potentially sensitive area, no further data are available for sharing.

Open Access This is an Open Access article distributed in accordance with the Creative Commons Attribution Non Commercial (CC BY-NC 4.0) license, which permits others to distribute, remix, adapt, build upon this work non-commercially, and license their derivative works on different terms, provided the original work is properly cited and the use is non-commercial. See: http://creativecommons.org/ licenses/by-nc/4.0/

\section{REFERENCES}

1 Turner-Stokes L, ed. Prolonged disorders of consciousness: national clinical guidelines. London: Royal College of Physicians, 2013.
2 NINDS Coma Information page: NIH—National Institute of Neurological Disorders and Stroke, 2015. http://www.ninds.nih.gov/disorders/coma/coma.htm (accessed 12 Nov 2016).

3 Strauss DJ, Shavelle RM, Ashwal S. Life expectancy and median survival time in the permanent vegetative state. Pediatr Neurol 1999;21:626-31.

4 Honeybul S, Gillett GR, Ho KM. Uncertainty, conflict and consent: revisiting the futility debate in neurotrauma. Acta Neurochir (Wien) 2016;158:1251-7.

5 Honeybul S, Gillett GR, Ho K. Futility in neurosurgery: a patient-centered approach. Neurosurgery 2013;73:917-22.

6 Gillett GR, Honeybul S, Ho KM, et al. Neurotrauma and the RUB: where tragedy meets ethics and science. J Med Ethics 2010;36:727-30.

7 Honeybul S, Gillett G, Ho K, et al. Ethical considerations for performing decompressive craniectomy as a life-saving intervention for severe traumatic brain injury. J Med Ethics 2012;38:657-61.

8 Honeybul S, Gillett GR, Ho KM, et al. Neurotrauma and the rule of rescue. J Med Ethics 2011;37:707-10.

9 The Mental Capacity Act. London: HMSO, 2005.

10 Kitzinger C, Kitzinger J. Family perspectives on 'proper medical treatment' for people in prolonged vegetative and minimally conscious states. In: Fovargue $S$, Mullock A, eds. The legitimacy of medical treatment: what role for the medical exception. London and New York: Routledge, 2015.

11 The legal context differs in Scotland. An account of this is given in Laurie GT, Harmon SHE, Porter G. Mason \& McCall Smith's law and medical ethics, 10th edn. OUP, 2016 paragraphs 15.121-15.127.

12 Practice Direction $9 \mathrm{E}$-Serious Medical Treatment. Supplements. Part 9 of the COP rules 2007. Updated 2015. https://www.judiciary.gov.uk/publications/practicedirection-9e-applications-relating-to-serious-medical-treatment-effective-from-1-july2015/ (accessed 12 Nov 2016).

13 Ruck-Keene A. Procedure, practice and legal requirements: a commentary on 'Why I wrote my advance decision'. J Med Ethics 2017;43:435-8.

14 Jackson P. Heart of England NHS Trust v JB [2014] EWHC 342 at para 2, 2014.

15 Formby A, Cookson R, Halliday S. Cost analysis of the legal declaratory relief requirement for withdrawing Clinically Assisted Nutrition and Hydration (CANH) from patients in the Permanent Vegetative State (PVS) in England and Wales. Centre for Health Economics Research Paper. York: University of York, 2015.

16 Kitzinger J, Kitzinger C. Causes and consequences of delays in treatment-withdrawal from PVS patients: a case study of Cumbria NHS Clinical Commissioning Group v Miss S and Ors [2016] EWCOP 32. J Med Ethics 2017;43:459-68.

17 Baker J. A matter of life and death. Oxford Shrieval lecture. Oxford: Courts and Tribunals Judiciary, 2016.

18 Ruck-Keene A. Advance Decisions to Refuse Life-Sustaining Treatment and the Court of Protection. Mental Capacity and the Law. 2016. http://www. mentalcapacitylawandpolicy.org.uk/advance-decisions-to-refuse-life-sustainingtreatment-and-the-court-of-protection/ (accessed 12 Nov 2016).

19 Advance decisions are legally binding: Compassion in dying, 2016. http:/l compassionindying.org.uk/advance-decisions-legally-binding/ (accessed 12 Nov 2016).

20 Bunn S, Fritz Z. Vegetative and minimally conscious states. Parliamentary office of science and technology. London: Parliament, 2015.

21 Kitzinger $C$, Kitzinger J. Withdrawing artificial nutrition and hydration from minimally conscious and vegetative patients: family perspectives. J Med Ethics 2015;41:157-16.

22 Giacino JT, Kalmar K. Diagnostic and prognostic guidelines for the vegetative and minimally conscious states. Neuropsychol Rehabil 2005;15:166-74. 